\title{
Association between ethnicity and risk factors for carotid artery stenosis: a retrospective study
}

\author{
ALMAS SHAMSHIYEV ${ }^{1, A, D, E}$, ABLAY TERGEUSSIZOV 2, A, B, E , ALZHAN BAUBEKOV 3, B, F,

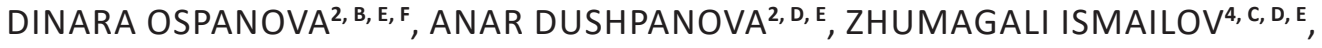 \\ ASKAR MATKERIMOV ${ }^{3, \mathrm{~B}, \mathrm{D}, \mathrm{F}}$, SHYNAR TANABAYEVA ${ }^{1, \mathrm{~B}, \mathrm{c}}$, ILDAR FAKHRADIYEV ${ }^{1, \mathrm{c}-\mathrm{F}}$ \\ ORCID ID: 0000-0003-1826-0460
}

${ }^{1}$ Department of Medicine, S. D. Asfendiyarov Kazakh National Medical University, Almaty, Kazakhstan ${ }^{2}$ Department of Medicine, Al-Farabi Kazakh National University, Almaty, Kazakhstan

${ }^{3}$ Department of Medicine, National Scientific Center of Surgery named after A. N. Syzganov, Almaty, Kazakhstan ${ }^{4}$ Department of Medicine, International Academy of Medicine and Sciences "Almaty Multi-profile Clinical Hospital", Almaty, Kazakhstan

A - Study Design, B - Data Collection, C - Statistical Analysis, D - Data Interpretation, E - Manuscript Preparation, F - Literature Search, G - Funds Collection

Summary Background. To date, the correlation between ethnicity and risk factors for the development of stenosis of the carotid arteries has not been evaluated in Kazakhstan.

Objectives. The study investigated the link between ethnicity and risk factors for the development of carotid artery stenosis ( $\geq 50 \%)$. Material and methods. The study is based on a retrospective analysis of the data of 356 patients hospitalized with suspected pathology of the carotid arteries. The patients were subdivided into groups according to their ethnic origin, age, and the degree of the narrowing of the internal carotid artery. The demographic data, main risk factors, and the effectiveness of treatment were analyzed.

Results. Among all the patients, Central Asians accounted for $56.5 \%$, Slavs for $35.9 \%$, and other nationalities for $7.6 \%$. A high level of obesity, hypertension and hypercholesterolemia, smoking, and low physical activity was prevalent in the group of the Central Asians. However, alcohol consumption was higher in the Slavs. Preventive use of aspirin prevailed in the Slavic patients (64.1\%). Male gender, hypercholesterolemia, and low physical activity were risk factors for the development of significant stenosis of the carotid arteries $(p<0.01)$.

Conclusions. The results showed that ethnicity, male gender, overweight, physical inactivity, smoking, and hypercholesterolemia were dominant risk factors for the development of significant carotid stenosis. Our findings indicate the need for the development of preventive measures to combat such risk factors in the amenable ethnic groups.

Key words: carotid artery diseases, carotid stenosis, stroke, ethnic groups, risk factors, Kazakhstan.

Shamshiyev A, Tergeussizov A, Baubekov A, Ospanova D, Dushpanova A, Ismailov Z, Matkerimov A, Tanabayeva S, Fakhradiyev I. Association between ethnicity and risk factors for carotid artery stenosis: a retrospective study. Fam Med Prim Care Rev 2021; 23(3): 354-362, doi: https://doi.org/10.5114/fmpcr.2021.108203.

\section{Background}

Stroke is one of the main causes of disability and decrease in life quality due to a long period of rehabilitation and various neurological complications [1-4]. Stroke is the second cause of death among all non-communicable diseases (after cardiovascular diseases) [5-7].

All risk factors for stroke development can be sub-divided into two groups: non-modifiable factors (age, gender, race, and the presence of hereditary diseases) and modifiable factors (the presence of diabetes, cardiovascular diseases, smoking, alcohol abuse, and metabolic disorders) [8].

Atherosclerosis of the arteries is one of the leading causes of the development of stroke [9]. Due to the fact that the atherosclerotic plaque formation in the lumen of the vessel is a dynamic process with alternating episodes of progression and healing, clinical manifestations can remain latent for a long time. In other words, atherosclerosis demonstrates prolonged manifestation before the development of complications, and this might take decades [10].

Given the fact that $85 \%$ of stroke cases are ischemic [11] and atherosclerosis-induced [12], timely treatment of carotid stenosis can reduce the rate of morbidity and mortality [13]. It has been demonstrated that the mechanism of stroke development is not hemodynamic in nature, but embolic. In this regard, the risk of stroke can be high due to the possibility of the detachment of atherosclerotic plaque, leading to the formation of a thrombus and vascular occlusion [14].

Nowadays, endarterectomy or stenting are recommended for the prevention of complications caused by carotid artery stenosis and reduction of the risk of severe stroke [15]. Taking into account the feasibility of vascular restenosis development (after surgery) [16], the development of the preventive measures aimed at lifestyle changes, as well as assessment and control of risk factors seem to be very important [17].

Up to date, in Kazakhstan, the risk factors for the development of stenosis of the carotid arteries caused by atherosclerotic vascular lesions have not yet been evaluated.

\section{Objectives}

The aim of this study was to assess the risk factors for the development of carotid artery stenosis caused by atherosclerotic vascular lesions in patients with pathology of the carotid ar- 
teries. The study focused on the association between ethnicity and risk factors for the development of carotid artery stenosis.

\section{Material and methods}

\section{Ethical considerations}

The study was approved by the Ethics Committee of the Kazakh Medical University of Continuing Education, Almaty, Kazakhstan (Protocol of the Local Ethics Commission No. 2 dated 13/12/2018).

\section{Data collection}

In the period from January 1, 2015 to December 31, 2019, at the JSC National Scientific Center of Surgery named after A. N. Syzganov (NSCS) (Almaty, Kazakhstan), 415 patients were hospitalized with suspected pathology of the carotid arteries (Figure 1). Among all the patients, 39 did not meet the inclusion criteria. The remaining patients $(n=376)$ underwent duplex vascular ultrasound (DUS) [18]. After DUS, two patients were excluded from the study due to non-atherosclerotic vascular lesions and fibromuscular dystrophy.

According to the results of DUS, stenosis of less than $50 \%$ was detected in 161 patients, in 207 patients with suspected significant stenosis equal to or greater than $50 \%$, and in six patients with an unspecified diagnosis. The latter were advised to undergo magnetic resonance angiography (MRA) or computed tomography (CT).
The results of the MRA or computed tomography angiography (CTA) study showed the presence of significant stenosis of the carotid arteries $(\geq 50 \%)$ in 195 patients. Stenosis of less than $50 \%$ was confirmed in 12 cases.

Thus, the study covered 161 patients with carotid stenosis of less than $50 \%$ and 191 patients with carotid stenosis of more than $50 \%$. The data of 356 patients were used and analyzed retrospectively.

Based on their ethnicity, the patients were subdivided into three ethnic groups: 1) "Central Asians", 2) "Slavs" and 3) "other nationalities". According to the data of national statistics, more than 130 nationalities live on the territory of Kazakhstan [19], including Central Asians (Kazakhs, Uzbeks, Tatars, Kyrgyz, Uighurs, Tajiks, Turkmen, etc.) and Slavs (Russians, Ukrainians, Belarusians, etc.). Other nationalities (Koreans, Germans, Azerbaijanis, Georgians, etc.) make up a small proportion of the population [19]. In this regard, the group of the Central Asians included Kazakhs, Uzbeks, Tatars, Kyrgyz, Uighurs, Tajiks, and Turkmens, etc. The group of the Slavs consisted of Russians, Ukrainians, Belarusians, etc. The group of other nationalities encompassed Koreans, Germans, Azerbaijanis, Georgians, and other national minorities.

Depending on age, the patients were divided into three categories: 1) < 55 years old, 2) 55-64 years old, and 3) > 65 years old. Gender was determined according to passport data. The patients were checked for the presence of concomitant cardioand cerebrovascular diseases, including hypertension, diabetes mellitus, and hypercholesterolemia. In addition, the factors influencing the risk of atherosclerosis, such as smoking, alcohol consumption, body mass index (BMI), and physical activity were also evaluated.

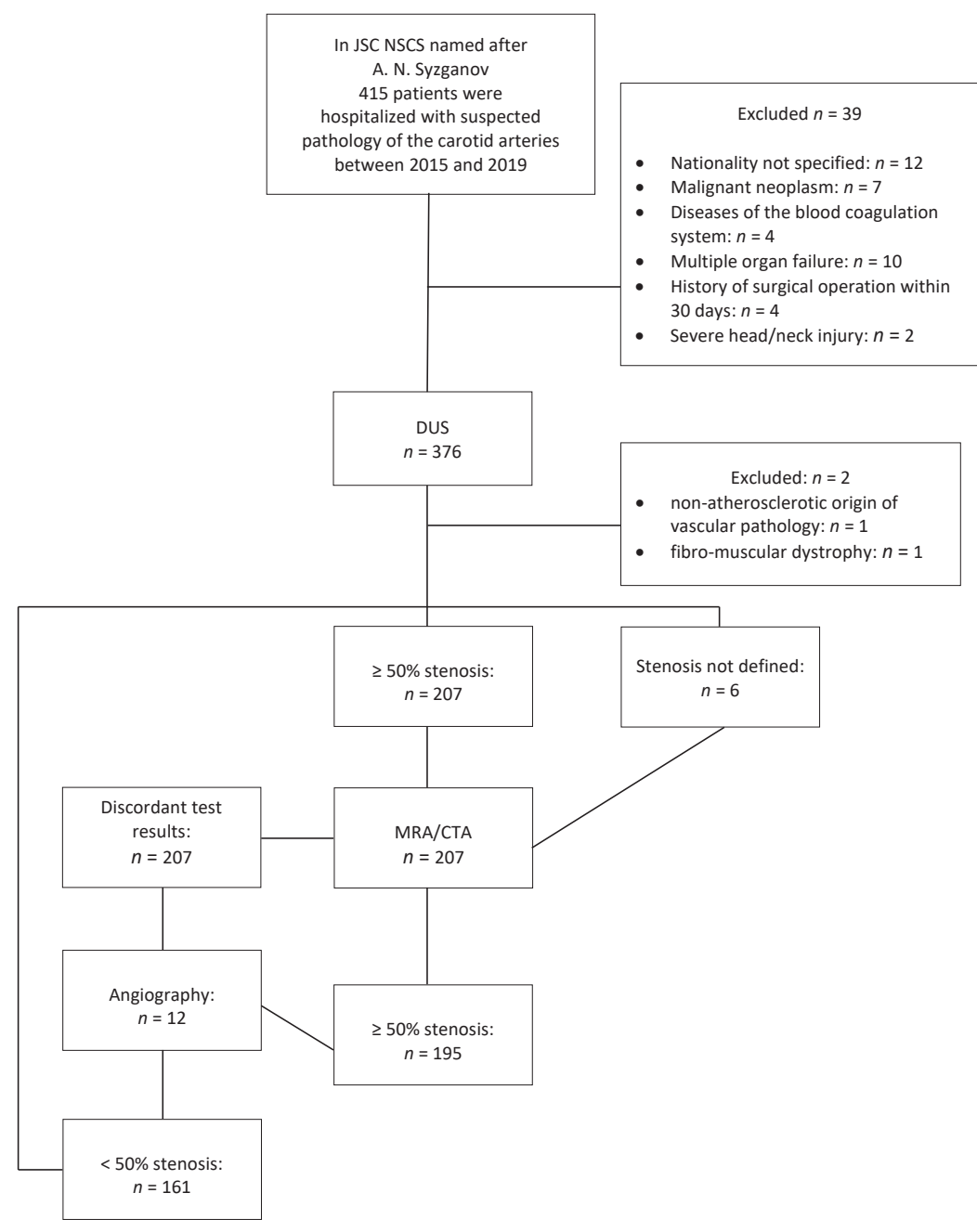

Figure 1. Flow chart of patients recruitment 
Physical activity scores were assessed using the International Questionnaire on Physical Activity (IPAQ). This questionnaire measures the time spent on physical activity of moderate, high intensity and at leisure in five sections: work, movement, at home, at leisure, and while sitting. The study used an adapted version of the IPAQ questionnaire in the Russian language [20].

The data on the registration of cases of stroke/transient ischemic attack (TIA) or myocardial infarction/coronary heart disease in the patients were also included in the study. To determine the level of neurological deficit after stroke, an assessment was carried out on the National Institutes of Health Stroke Scale (NIHSS) [21]. The scale consists of 15 indicators to characterize the main functions. The absence of changes in the neurological status was assessed as 0 points, while the death of the patient was expressed as 31 points. The results were evaluated by points: 0 points - satisfactory condition; $1-4$ points - mild stroke; 5-15 points - a stroke of moderate severity; 16-20 points - a condition between moderate and severe stroke; and 21-42 points - severe stroke.

Apart from that, we also analyzed the frequency of preventive administration of medications in the patients, including antihypertensive drugs, antiplatelet drugs, anticoagulants, and statins.

Depending on the degree of the narrowing of the internal carotid artery, the patients were sub-divided into two subgroups: the first group with "no narrowing" (the narrowing of the lumen of the carotid artery was equal to or less than 50\%), and the second group with "significant narrowing" (equal to or greater than $50 \%$ ).

All the patients were treated according to the approved clinical protocol of the Ministry of Health of the Republic of Kazakhstan [22] based on the North American Symptomatic Carotid Endarterectomy Trial (NASCET) criteria [23] and European Carotid Surgery Trial (ECST) platform [24]. In cases of controversial situations, the decision on the type of operation and the method of treatment was made collectively.

Ultrasound evaluation of carotid artery atherosclerotic disease was the main screening method for carotid artery stenosis in the study. The Philips Affinity 70 (2006) (Netherlands) device was employed for ultrasonic examination [18].

Angiography was performed using the SIEMENS AXIOM Artis dFC cardiovascular system (Germany). Angiographic calculation of the percentage of the internal carotid artery (ICA) stenosis according to the NASCET criterion [25] used the following formula: \% ICA stenosis = (1 - [narrowest ICA diameter/diameter of normal distal cervical ICA]) $\times 100$.

\section{Statistical analysis}

Statistical analysis was performed using the IBM SPSS Statistics V22.0 statistical software (USA). Results are presented as $\mathrm{M} \pm$ SD. Qualitative characteristics were described in absolute $(n)$ and relative values (\%). One-dimensional analysis of variance ANOVA was chosen for the statistical test, since the samples from the groups were independent. The Tukey HSD for the unequal test was used to check for paired differences since there was a difference in the number of patients in each group. The univariate analysis was adjusted for age and sex. The $\chi^{2}$ test was utilized to establish the statistical significance of differences between the groups depending on the degree of the narrowing of the internal carotid artery.

Among all the ethnic groups, multivariate logistic regression analysis for risk factors stenosis ( $\geq 50 \%$ ) was performed, and $p<0.05$ was considered statistically significant for all analyses.

\section{Results}

\section{Clinical and demographic characteristics}

Among the 356 patients included in the study, the distribution by ethnicity was as follows: $n=201$ (56.5\%) were Central Asians, $n=128$ (35.9\%) were Slavs, and $n=27$ (7.6\%) were representatives of other nationalities (Table 1). In general, no statistically significant differences were found between the three age groups.

\begin{tabular}{|c|c|c|c|c|c|}
\hline \multirow[t]{2}{*}{ Characteristics } & \multicolumn{3}{|l|}{ Ethnicity } & \multirow{2}{*}{$\begin{array}{l}\text { Total } \\
n=356\end{array}$} & \multirow[t]{2}{*}{$p$} \\
\hline & $\begin{array}{l}\text { Central Asians } \\
n=201 \text { (56.5) }\end{array}$ & $\begin{array}{l}\text { Slavs } \\
n=128(35.9)\end{array}$ & $\begin{array}{l}\text { Others } \\
n=27(7.6)\end{array}$ & & \\
\hline $\begin{array}{l}\text { Age } \\
<55 \\
55-64 \\
>65\end{array}$ & $\begin{array}{l}15(8 \%) \\
65(32 \%) \\
121(60 \%)\end{array}$ & $\begin{array}{l}18(15 \%) \\
32(25 \%) \\
78(60 \%)\end{array}$ & $\begin{array}{l}5(18.5 \%) \\
10(37 \%) \\
12(44.5 \%)\end{array}$ & \begin{tabular}{|l|}
$38(10.7 \%)$ \\
$107(30 \%)$ \\
$211(59.3 \%)$
\end{tabular} & $\begin{array}{l}0.06 \\
0.87 \\
0.97\end{array}$ \\
\hline $\begin{array}{l}\text { Sex } \\
\text { male } \\
\text { female }\end{array}$ & $\begin{array}{l}140(69.7) \\
61(30.3) \\
\end{array}$ & $\begin{array}{l}83(64.8) \\
45(35.2) \\
\end{array}$ & $\begin{array}{l}15(55.6) \\
12(44.4) \\
\end{array}$ & \begin{tabular}{|l|}
$238(66.9)$ \\
$118(33.1)$ \\
\end{tabular} & \begin{tabular}{|l}
0.75 \\
0.65 \\
\end{tabular} \\
\hline $\begin{array}{l}\text { Body mass index } \\
<25 \\
25-29.9 \\
>30 \\
\end{array}$ & \begin{tabular}{|l|}
$21(10.5)$ \\
$62(30.8)$ \\
$118(58.7)$ \\
\end{tabular} & $\begin{array}{l}65(50.8) \\
26(20.3) \\
37(28.9) \\
\end{array}$ & $\begin{array}{l}5(18.5) \\
13(48.2) \\
9(33.3) \\
\end{array}$ & \begin{tabular}{|l|}
$91(25.5)$ \\
$101(28.4)$ \\
$164(46.1)$ \\
\end{tabular} & \begin{tabular}{|l|}
0.01 \\
0.01 \\
0.001 \\
\end{tabular} \\
\hline $\begin{array}{l}\text { Concomitant disorder } \\
\text { hypertension } \\
\text { hypercholesterolemia } \\
\text { diabetes }\end{array}$ & $\begin{array}{l}149(74.1) \\
167(83.1) \\
37(18.4) \\
\end{array}$ & 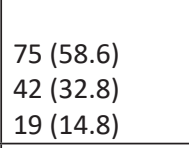 & \begin{tabular}{|l|}
$21(77.7)$ \\
$12(44.4)$ \\
$4(14.8)$ \\
\end{tabular} & $\begin{array}{l}245(68.8) \\
221(62.1) \\
60(16.8) \\
\end{array}$ & $\begin{array}{l}0.05 \\
0.01 \\
0.28 \\
\end{array}$ \\
\hline $\begin{array}{l}\text { Smoking } \\
\text { non-smokers } \\
\text { former smokers } \\
\text { current smokers } \\
\end{array}$ & $\begin{array}{l}109(54.2) \\
31(15.4) \\
61(30.4) \\
\end{array}$ & \begin{tabular}{|l|}
$87(68.0)$ \\
$9(7.0)$ \\
$32(25.0)$ \\
\end{tabular} & \begin{tabular}{|l}
$7(25.9)$ \\
$5(18.5)$ \\
$14(51.9)$ \\
\end{tabular} & \begin{tabular}{|l}
$203(57.0)$ \\
$45(12.6)$ \\
$107(30.1)$ \\
\end{tabular} & $\begin{array}{l}0.07 \\
0.45 \\
0.05 \\
\end{array}$ \\
\hline $\begin{array}{l}\text { Alcohol consumption } \\
\text { never drinks } \\
\text { former drinker } \\
\text { drinks }\end{array}$ & $\begin{array}{l}87(43.3) \\
75(37.3) \\
39(19.4) \\
\end{array}$ & $\begin{array}{l}19(14.8) \\
68(53.1) \\
41(32.1) \\
\end{array}$ & $\begin{array}{l}16(59.3) \\
5(18.5) \\
6(22.2) \\
\end{array}$ & \begin{tabular}{|l|}
$122(34.3)$ \\
$148(41.5)$ \\
$86(24.2)$ \\
\end{tabular} & \begin{tabular}{|l|}
0.001 \\
0.01 \\
0.01 \\
\end{tabular} \\
\hline $\begin{array}{l}\text { Physical activity (SD)* } \\
\text { 18-40 y.o.* } \\
40-65 \text { y.o.* } \\
>65 \text { y.o. }{ }^{*}\end{array}$ & $\begin{array}{l}24.8 \pm 4.8 \\
15.3 \pm 2.2 \\
5.1 \pm 1.6\end{array}$ & $\begin{array}{l}25.1 \pm 3.2 \\
17.3 \pm 5.1 \\
7.2 \pm 2.4\end{array}$ & $\begin{array}{l}25.4 \pm 0.9 \\
16.7 \pm 1.1 \\
8.1 \pm 1.7\end{array}$ & $\begin{array}{l}26.7 \pm 6.8 \\
18.1 \pm 5.9 \\
7.9 \pm 3.3\end{array}$ & $\begin{array}{l}0.56 \\
0.05 \\
0.01\end{array}$ \\
\hline
\end{tabular}




\begin{tabular}{|c|c|c|c|c|c|}
\hline \multirow[t]{2}{*}{ Characteristics } & \multicolumn{3}{|l|}{ Ethnicity } & \multirow{2}{*}{$\begin{array}{l}\text { Total } \\
n=356\end{array}$} & \multirow[t]{2}{*}{$p$} \\
\hline & $\begin{array}{l}\text { Central Asians } \\
n=201 \text { (56.5) }\end{array}$ & \begin{tabular}{|l|} 
Slavs \\
$n=128(35.9)$ \\
\end{tabular} & $\begin{array}{l}\text { Others } \\
n=27(7.6)\end{array}$ & & \\
\hline Previous stroke/TIA & $21(10.4)$ & $15(11.7)$ & $2(7.4)$ & $38(10.7)$ & 0.31 \\
\hline Previous MI/IHD & $17(8.5)$ & $14(10.9)$ & $1(3.7)$ & $32(8.9)$ & 0.78 \\
\hline Stroke scale NIHSS (SD)* & $7.3 \pm 3.2$ & $5.1 \pm 2.4$ & $5.3 \pm 1.9$ & $5.7 \pm 2.1$ & 0.05 \\
\hline $\begin{array}{l}\text { Antiplatelet therapy before admission } \\
\text { Aspirin } \\
\text { Clopidogrel } \\
\text { Combination }\end{array}$ & $\begin{array}{l}75(37.3) \\
11(5.5) \\
7(3.5)\end{array}$ & $\begin{array}{l}82(64.1) \\
6(4.7) \\
2(1.6) \\
\end{array}$ & $\begin{array}{l}17(80) \\
2(7.4) \\
2(7.4)\end{array}$ & $\begin{array}{l}46(12.9) \\
19(5.3) \\
11(3.1) \\
\end{array}$ & $\begin{array}{l}0.01 \\
0.98 \\
0.66\end{array}$ \\
\hline $\begin{array}{l}\text { Other therapy before admission } \\
\text { Warfarin } \\
\text { antihypertensive drugs } \\
\text { statins }\end{array}$ & $\begin{array}{l}4(1.9) \\
158(78.6) \\
102(50.7)\end{array}$ & $\begin{array}{l}2(1.6) \\
98(76.6) \\
38(29.7)\end{array}$ & $\begin{array}{l}2(7.4) \\
24(88.8) \\
9(33.3)\end{array}$ & $\begin{array}{l}8(2.2) \\
280(78.6) \\
149(41.8)\end{array}$ & $\begin{array}{l}0.90 \\
0.87 \\
\mathbf{0 . 0 0 1}\end{array}$ \\
\hline
\end{tabular}

* One-dimensional analysis of variance ANOVA, TIA - transient ischemic attack, MI - myocardial infarction, IHD - ischemic heart disease, NIHSS - National Institutes of Health Stroke Scale.

The proportion of women was higher in all groups $(66.9 \%$ of all cases). Among the men of Slavic nationality $(n=83)$, there were fewer patients in comparison with the men from Central Asia $(n=140)(p=0.75)$.

The number of the Slavs with normal weight $(\mathrm{BMI}<25)$ was higher ( $n=65$ or $50.8 \%$ ) compared with the Central Asians ( $n=21$ or $10.5 \%)(p=0.05)$. Overweight (BMI $=25-29.9)$ among the Central Asians $(n=62)$ prevailed in comparison with the Slavs $(n=26)$ and with other nationalities $(n=13)(p=0.01)$. The presence of obesity ( $\mathrm{BMI}>30$ ) was statistically significantly higher among the Central Asians $n=118$ (58.7\%) than among the Slavs $n=37(28.9 \%)(p=0.001)$.

Hypertension and hypercholesterolemia were the prevailing factors in all the ethnic groups with incidence rates of $68.8 \%$ and $62.1 \%$, respectively. Hypertension among the Slavs $(n=75$ or $58.6 \%$ ) was less common in contrast to other ethnic groups ( $n=21$ or $77.7 \%$ ) and the Central Asians ( $n=149$ or $74.1 \%$ ) with a statistically significant difference $(p=0.05)$. In addition, hypercholesterolemia was more often observed in the Central Asians ( $n=167$ cases), in contrast to the two ethnic groups $(p=0.01)$.

Among all the patients, the number of smokers (30.1\%) was almost twice as high as that of non-smokers (57\%). Among the Central Asians, there were more active smokers $(n=61)$ in comparison with the Slavs $(n=32)$ and other ethnic groups $(n=14)$ with a statistically significant difference $(p=0.05)$.

Regarding the frequency of alcohol consumption during the study period, the number of patients from the Slavic ethnic group with an indicator of $32.1 \%$ was higher than the number of the Central Asians (19.4\%) and other nationalities (22.2\%) $(p=0.01)$. Therefore, there was an overwhelming majority among non-drinking Central Asians $(n=87)$ and people of other nationalities $(n=16)$ compared to the Slavs $(n=19)(p=0.001)$.

The results based on the IPAQ questionnaire showed that, in the group of patients over 65, the Central Asians had the lowest indicator of physical activity $(5.1 \pm 1.6)$ in comparison with the Slavs and other ethnic groups with indicators of $7.2 \pm 2.4$ and $8.1 \pm 1.7(p=0.01)$. Moreover, comparatively low IPAQ scores among the Central Asians were found in the age range of 40-65, in contrast to the two ethnic groups $(p=0.05)$.

According to the NIHSS stroke scale, in all three ethnic groups, the mean score was about $5.7 \pm 2.1$. However, in the Central Asians (7.3 \pm 3.2 ), this score was higher compared to the other two ethnic groups, which was regarded as a statistically significant difference $(p=0.05)$.

The use of aspirin before re-vascularizing surgery with a statistically significant difference was higher in the patients from the Slavic ethnic group (82 [64.1\%]) than in the Central Asians (75 [37.3\%]). Nevertheless, other ethnic groups used this drug more often than the Slavs $(n=17$ or $80 \%)(p=0.01)$.
Before surgical treatment, statins were often used in the Central Asians ( $n=102$ or $50.7 \%$ ) compared to the patients of other nationalities ( $n=9$ or $33.3 \%)$ and the Slavs $(n=38$ or $29.7 \%)(p=0.001)$.

\section{Assessment of the risk of developing carotid stenosis}

The characteristics of the influence of risk factors by the degree of stenosis of the carotid arteries are presented in Table 2. According to the results of angiography, $54.8 \%(n=195)$ of the patients were diagnosed with a significant narrowing of the lumen of the carotid artery ( $\geq 50 \%)$, and the absence of the narrowing $(\leq 50 \%)$ was recorded in $45.2 \%(n=161)$ of the cases.

The findings of the study indicate that gender plays a significant role in developing carotid atherosclerosis and narrowing of the lumen of the vessel. We observed that men were more predisposed to these symptoms than women $(\geq 50 \%)(p=0.001)$.

Our data indicate that hypertension and hypercholesterolemia prevailed in Central Asians in comparison with other ethnic groups (with or without the narrowing of the carotid artery). However, hypertension as a possible risk factor for the development of carotid artery stenosis did not affect the degree of the narrowing. The total number of patients from all the three ethnic groups diagnosed with hypertension was higher in the subgroup "without significant stenosis" $(\leq 50 \% ; n=135)$ than in the "carotid artery narrowing" sub-group ( $\geq 50 \% ; n=63)(p=0.05)$. However, in the group of patients with a significant narrowing of the carotid artery ( $n=125$ or $64.1 \%$ ), hypercholesterolemia was detected more often $(p=0.001)$ compared to the subjects without the narrowing of the artery ( $n=96$ or $59.6 \%$ ).

The presence of diabetes mellitus was higher in the group of patients without the narrowing of the carotid arteries (33.3\%) than in the patients with significant stenosis $(16.8 \%)(p<0.05)$.

We found that the presence of transient ischemic attack (TIA) $(p=0.55)$, myocardial infarction and coronary artery disease $(p=0.75)$ in the patient's medical history did not have any correlation with the degree of the narrowing of the lumen of the carotid arteries.

Smoking as a risk factor considerably increased the incidence of major narrowing of the carotid arteries. The number of smokers in the group of carotid artery narrowing above $50 \%$ $(n=82)$ was greater than in patients without significant stenosis $(<50 \%)(n=25)(p=0.01)$. In addition, in the "non-smokers" group, in $75.8 \%$ of cases, the narrowing of the lumen of the carotid arteries was diagnosed in no more than $50 \%$ of the cases, and stenosis equal to or greater than $50 \%$ was found in $42.1 \%$ of the patients $(p=0.05)$. 


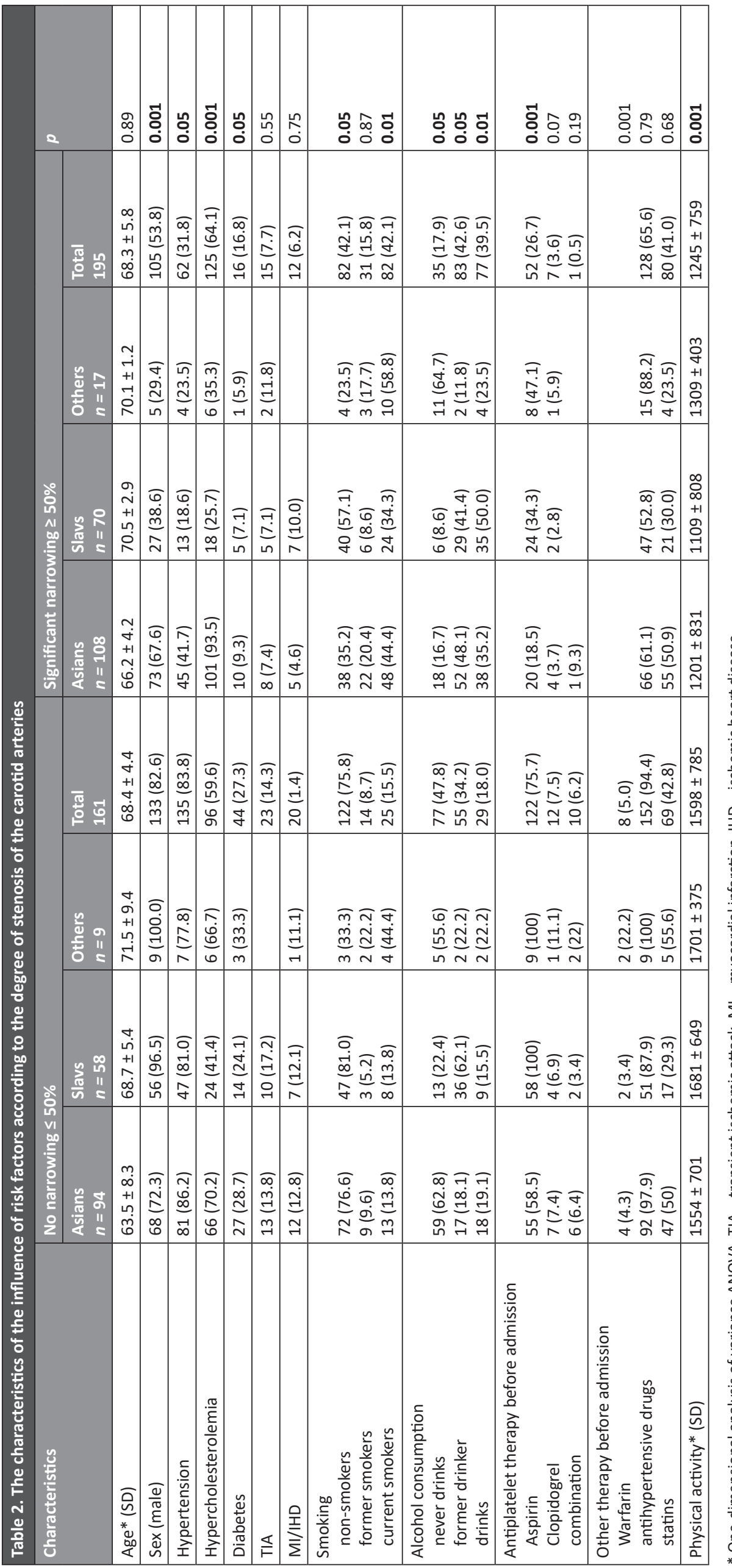




\begin{tabular}{|c|c|c|c|c|c|c|c|c|c|}
\hline & \multicolumn{3}{|l|}{ Asians } & \multicolumn{3}{|l|}{ Slavs } & \multicolumn{3}{|c|}{ Others } \\
\hline & OR & $95 \% \mathrm{Cl}$ & $p^{*}$ & OR & $95 \% \mathrm{Cl}$ & $p^{*}$ & OR & $95 \% \mathrm{Cl}$ & $p^{*}$ \\
\hline $\begin{array}{l}\text { Age } \\
<55 \\
55-64 \\
>65 \\
\end{array}$ & $\begin{array}{l}1.892 \\
1.718 \\
1.612 \\
\end{array}$ & $\begin{array}{l}2.430-4.662 \\
1.554-4.380 \\
0.760-3.323 \\
\end{array}$ & $\begin{array}{l}0.002 \\
0.541 \\
0.001 \\
0.004 \\
\end{array}$ & \begin{tabular}{|l|}
1.761 \\
1.064 \\
0.484 \\
\end{tabular} & $\begin{array}{l}1.645-3.642 \\
0.505-2.657 \\
0.213-1.607\end{array}$ & $\begin{array}{l}0.05 \\
0.129 \\
0.041 \\
0.007 \\
\end{array}$ & $\begin{array}{l}1.711 \\
1.682 \\
1.031 \\
\end{array}$ & $\begin{array}{l}1.446-3.254 \\
0.724-3.214 \\
0.264-2.714 \\
\end{array}$ & $\begin{array}{l}0.321 \\
0.246 \\
0.227 \\
0.752 \\
\end{array}$ \\
\hline Sex (male) & 0.673 & $0.524-0.881$ & 0.001 & 1.823 & $1.248-2.664$ & 0.021 & 0.582 & $0.531-0.984$ & 0.052 \\
\hline $\begin{array}{l}\text { Body mass index } \\
<25 \\
25-29.9 \\
>30 \\
\end{array}$ & $\begin{array}{l}0.871 \\
0.978 \\
1.126 \\
\end{array}$ & $\begin{array}{l}0.717-1.274 \\
0.824-1.324 \\
0.958-1.548 \\
\end{array}$ & $\begin{array}{l}0.745 \\
0.024 \\
0.001 \\
\end{array}$ & \begin{tabular}{|l|}
1.197 \\
1.459 \\
0.824 \\
\end{tabular} & $\begin{array}{l}0.768-1.522 \\
0.687-1.452 \\
0.527-1.261 \\
\end{array}$ & \begin{tabular}{|l|}
0.335 \\
0.682 \\
0.032 \\
\end{tabular} & $\begin{array}{l}1.201 \\
1.719 \\
1.376 \\
\end{array}$ & $\begin{array}{l}0.967-1.891 \\
1.167-2.422 \\
1.078-2.016 \\
\end{array}$ & $\begin{array}{l}0.546 \\
\mathbf{0 . 0 0 1} \\
\mathbf{0 . 0 1 3} \\
\end{array}$ \\
\hline Smoking & 1.133 & $0.877-1.614$ & 0.023 & 3.789 & $2.174-5.618$ & 0.001 & 1.201 & $0.741-1.358$ & 0.429 \\
\hline Alcohol & 1.109 & $0.836-1.421$ & 0.578 & 1.251 & $0.721-1.982$ & 0.014 & 0.759 & $0.478-1.201$ & 0.727 \\
\hline Hypertension & 0.875 & $0.622-1.141$ & 0.525 & 1.928 & $1.657-3.201$ & 0.061 & 1.178 & $0.489-2.455$ & 0.511 \\
\hline Hypercholesterolemia & 0.809 & $0.524-0.872$ & 0.001 & 2.357 & $1.793-4.547$ & 0.001 & 0.647 & $0.368-1.159$ & 0.028 \\
\hline Diabetes & 0.854 & $0.673-1.183$ & 0.208 & 1.209 & $0.724-2.119$ & 0.724 & 0.798 & $0.327-1.425$ & 0.637 \\
\hline TIA & 1.143 & $0.864-1.185$ & 0.631 & 1.128 & $0.672-1.769$ & 0.751 & 0.798 & $0.509-1.109$ & 0.414 \\
\hline $\mathrm{MI} / \mathrm{IHD}$ & 1.325 & $1.174-1.940$ & 0.785 & 1.241 & $0.852-1.753$ & 0.622 & 0.823 & $0.689-1.029$ & 0.627 \\
\hline
\end{tabular}

$* p<0.05$ was considered statistically significant, TIA - transient ischemic attack, MI - myocardial infarction, IHD - ischemic heart disease.

There were more patients who consumed alcohol in the group with substantial narrowing of the carotid arteries 77 (39.5\%) compared with the group without stenosis 29 (18.0\%). These findings indicate a statistically significant increase in the risk of developing stenosis by about $50 \%(p=0.01)$.

The results demonstrated that preliminary administration of clopidogrel (or its combination with aspirin) did not reduce the incidence of carotid stenosis $(p>0.05)$. However, the selective administration of aspirin as antiplatelet therapy was able to prevent the development of significant narrowing of the carotid artery in $75.7 \%(n=122)$ of the cases. It was considered a statistically significant difference $(p=0.001)$. Among other medications used for preventive therapy, warfarin was shown to be effective in reducing the incidence of significant stenosis in $n=8(5 \%)$ cases $(p=0.001)$. Despite the more frequent use of antihypertensive drugs $(94.4 \%)$ in the group with carotid artery stenosis was less than $50 \%$, in comparison to the patients in the group with significant stenosis $(65.6 \%)$, no statistically significant differences were found ( $p=0.79)$.

According to the IPAQ questionnaire, the total physical activity score of patients with a vascular lumen narrowing of $\geq 50 \%$ (1245 \pm 759 ) was statistically significantly lower in comparison with the respondents with a decrease in the lumen equal to or less than $50 \%(1598 \pm 785)$ the carotid arteries (based on the angiography results) $(p=0.001)$.

In addition, we employed a multivariate logistic regression analysis (Table 3 ) to all identified risk factors in order to identify any existing differences. This analysis can facilitate the understanding of the difference in the prevalence of carotid stenosis among all the ethnic groups.

In the Asian ethnic group, belonging to the age group of 55-64 (OR 1.718; 95\% Cl: 1.554-4.380; $p=0.001$ ) was the most significant risk factor for stenosis ( $\geq 50 \%$ ). Male gender was a significant risk factor in the Asians (OR 0.673; $95 \% \mathrm{Cl}$ : $0.524-0.881 ; p=0.001$ ), as well as in the Slavs (OR 1.823; 95\% $\mathrm{Cl}: 1.248-2.664 ; p=0.021$ ). According to $\mathrm{BMI}$, overweight (OR 1.719; 95\% Cl: 1.167-2.422; $p=0.001$ ) and obesity (OR 1.376; 95\% Cl: $1.078-2.016 ; p=0.013)$ were significant risk factors for stenosis ( $\geq 50 \%$ ) in the "other ethnic group" only.

Smoking as a risk factor was identified in the Slavs (OR 3.789; 95\% Cl: 2.174-5.618), with confidence $p=0.001$. The presence of hypercholesterolemia was identified as a significant risk factor in the Asians (OR 0.809; 95\% Cl: 0.524-0.872; $p=0.001$ ) and among the Slavs (OR 2.357; 95\% Cl: 1.793-4.547; $p=0.001$ ).

\section{Discussion}

To the best of our knowledge, this is the first analysis of the correlation between ethnicity and risk factors of the development of stenosis of the carotid arteries in the Republic of Kazakhstan. The percentage of men who required re-vascularizing surgery was $66.9 \%$ (for all the three ethnic groups), but there was no statistically significant difference. The data quoted in previous studies demonstrated the high morbidity in men compared with women [26, 27]. This observation could be explained by the prevalence of possible risk factors, such as concomitant cardiovascular diseases and bad habits that dominated mainly in the men population [28].

A growing body of evidence suggests that smoking, in association with other risk factors, significantly increases the risks of developing carotid artery stenosis due to atherosclerosis [29]. Previous studies also showed that among smokers the percentage of men exceeds the proportion of women. In this regard, smoking can be considered as a significant factor of recurrent stroke development due to stenosis of the carotid arteries [30]. This mechanism can be explained by the fact that tobacco triggers atherosclerotic lesions formation, thus increasing the risk of thrombosis [31]. Our outcomes demonstrate that the number of active smokers (and ex-smokers as well) was high among the Central Asians.

Despite a qualitative assessment of the status of a smoker presented in this study, previous studies have also shown that smoking only one cigarette a day carries a great risk of developing coronary heart disease and stroke [32].

As for the use of alcohol, the number of patients who absolutely do not drink alcohol was high among the Central Asians compared to the Slavs in the context of the effect of alcohol consumption on the narrowing of the carotid arteries. Our results showed that the frequency of vascular stenosis was higher in patients who regularly drink alcohol. Previous studies indicated that episodic alcohol consumption less than $2.5 \mathrm{~g}$ of alcohol per day does not affect the process of vascular atherogenesis. However, regular consumption of alcoholic beverages can lead to the activation of this process [33].

In this study, the results of angiography revealed significant narrowing of the carotid artery ( $\geq 50 \%)$ in 195 out of 356 subjects (54.8\%). Previously, it has been shown that the prevalence of carotid artery stenosis over $50 \%$ is relatively high among 
women. It was also demonstrated that patients with stenosis of the carotid artery were older than the control group $(71.7 \pm 11$ vs $66.3 \pm 12$ years) [34].

According to our findings, most of the patients were over 65 years old (in $59.3 \%$ of all the cases), particularly among the group of the Central Asian patients (60\%). In fact, the increase in the development of stroke has been associated with an increase in age. In a previous study, Xia et al. demonstrated that the prevalence of stroke in patients over 60 years old was $4.94 \%$, and it can be related to the fact that with increasing age, other risk factors are also higher [35].

The outcomes of this study showed that hypertension and hypercholesterolemia were the prevailing diseases in all the ethnic groups (in comparison with diabetes mellitus). It was reported that the presence of diabetes can increase the risk of developing stenosis of the carotid arteries [26], including an increase in the risk of developing a second stroke [36]. In fact, hypercholesterolemia plays an important role in the development of ischemic stroke, while hypertension triggers the manifestation of hemorrhagic stroke in most cases [37]. According to the results obtained, the presence of hypertension and hypercholesterolemia prevailed in the Central Asian patients. However, hypercholesterolemia likely causes significant stenosis of the carotid artery (64.1\%) in comparison with high blood pressure.

Despite all the identified factors (age, male gender, obesity, overweight, smoking, alcohol, diabetes, and hypercholesterolemia) for the development of carotid artery stenosis of $50 \%$ or more, regression analysis revealed that age over 65 was a significant risk factor only in the group of other nationalities. At the same time, male gender increased the risk of stenosis by $\geq 50 \%$ only in the groups of the Central Asians and the Slavs. Alcohol consumption was not identified as a risk factor for stenosis of $50 \%$ or more in all the groups. However, smoking was determined as a significant risk factor for stenosis in the Slavs. In addition, hypercholesterolemia increased the risk of developing stenosis by $\geq 50 \%$ only in the groups of the Central Asians and the Slavs. Such findings might be explained by a small sample size of our study, which led to a decrease in the level of statistical significance of some factors.

The results demonstrated that a narrowing of the carotid artery the lumen equal to or less than $50 \%$ was associated with the preventive administration of aspirin. However, we found that patients with the carotid artery $\geq 50 \%$ did not take aspirin at all. Such results indicate the problem with screening and prevention of cardiovascular diseases in Kazakhstan, which requires the improvement and optimization of the approaches for the diagnostics, treatment and monitoring at the level of primary care. However, the administration of drugs such as antihypertensive drugs, clopidogrel and statins did not show a preventive therapeutic effect in reducing the incidence of carotid artery stenosis.

In fact, there is a range of reports discussing the role of statins in preventing carotid pathologies and highlighting their role in reducing the risk of ischemic stroke [38]. Some of them indicate that statins have an impact on the regression of pathological changes in the carotid artery [39]. However, our data did not support the previous reports on the therapeutic efficacy of the combination of aspirin and clopidogrel [40]. Moreover, our findings are in line with the results of other studies [41], where the question of the optimal treatment of carotid disease still remains controversial.

Apart from the effect of pharmacological agents, the negative effect of low physical activity and sedentary lifestyle on the risk of developing carotid atherosclerosis has also been previously reported [42]. In fact, compared to the Slavs and repre- sentatives of other ethnic groups, the Central Asians had a low level of physical activity. Despite the fact that the questionnaire used in the study was based on the assessment of physical activity over the preceding week, it still allows identifying persons with physical inactivity [43].

In our study, BMI indicators above 30 were generally observed in $46.1 \%$ of the cases, and among the Central Asians, this indicator was $58.7 \%$. It is worth noting that a carotid artery narrowing of $50 \%$ or more was diagnosed often among the Central Asians with high BMI and physical inactivity (with a statistically significant difference). These findings may confirm the hypothesis that excessive weight is one of the main risk factors for the development of carotid stenosis of the arteries and for stroke.

We assume that such an observation is associated with differences in dietary preferences among different ethnic groups [44]. Representatives of Central Asian ethnic groups usually consume large quantities of meat products, unlike other ethnic groups. There are some reports indicating that people who eat meat on a regular basis are not predisposed to a high risk of stroke (as opposed to vegetarians) [45]. However, further research is needed to explain the high risk of stroke among Central Asians.

Our data indicate that carotid stenosis was found in patients with non-specific symptoms (dizziness, subjective weakness, and fainting or fainting attacks), despite the fact that such patients had asymptomatic type of the disease [1].

It should be noted that most of the risk factors for atherosclerosis are modifiable [46], and atherosclerosis of the carotid arteries is the cause of ischemic stroke in $20 \%$ of the cases [47]. Taking into account these facts, it is necessary to develop effective preventive measures to reduce the incidence of heart disease. Our findings suggest the need for extensive randomized controlled trials to identify risk factors depending on ethnic groups.

\section{Limitations of the study}

Our study had several limitations. First of all, this study was from a single center (hence the small sample size). In addition, the IPAQ-SF questionnaire cannot be considered an ideal tool for such research [48]. Consequently, more validated instruments and methods for the evaluation of physical activity should be used in the future. It should be noted that peripheral artery disease was present in $18 \%-22 \%$ of the patients [49], so there is a need to estimate the prevalence of patient's lower extremities atherosclerosis by measuring it with the Ankle Brachial Index (Ankle Brachial Index is a good parameter for identifying high cardiovascular risk) [50].

\section{Conclusions}

Our retrospective analysis showed that there was a predominance of Central Asians in the cohort of patients hospitalized with suspected pathology of the carotid arteries in Kazakhstan (2017-2019). Male gender, overweight, physical inactivity and hypercholesterolemia were dominant among all risk factors for the development of significant carotid stenosis. These findings require further research to develop a prevention strategy for combating these risk factors in the target group.

Acknowledgments. The authors express their gratitude to Dr. Timur Saliev for his valuable assistance in the process of writing and language editing of the manuscript and to S. D. Asfendiyarov Kazakh National Medical University for the provision of administrative and technical support. 


\section{References}

1. Mortimer R, Nachiappan S, Howlett DC. Carotid artery stenosis screening: where are we now? Br J Radio/ 2018; 91(1090): 20170380, doi: 10.1259/bjr.20170380.

2. Alzamel N, Qureshi AZ, Rathore FA, et al. The negative effects of anterior cruciate ligament injury during stroke rehabilitation. Pak J Med Sci 2019; 35(6): 1740-1744, doi: 10.12669/pjms.35.6.974.

3. Cunha DD, Camargos S, Passos VMD, et al. Heterotopic ossification after stroke: clinical profile and severity of ossification. J Stroke Cerebrovasc 2019; 28(2): 513-520, doi: 10.1016/j.jstrokecerebrovasdis.2018.10.032.

4. Handelzalts S, Melzer L, Soroker N. Analysis of brain lesion impact on balance and gait following stroke. Front Hum Neurosci 2019; 13: 149, doi: 10.3389/fnhum.2019.00149.

5. Jackson CA, Kerssens J, Fleetwood K, et al. Incidence of ischaemic heart disease and stroke among people with psychiatric disorders: retrospective cohort study. Brit J Psychiat 2020; 217(2): 442-449, doi: 10.1192/bjp.2019.250.

6. Hamad R, Penko J, Kazi DS, et al. Association of low socioeconomic status with premature coronary heart disease in US Adults. Jama Cardiol 2020; 5(8): 899-908, doi: 10.1001/jamacardio.2020.1458.

7. Avan A, Digaleh H, Di Napoli $M$, et al. Socioeconomic status and stroke incidence, prevalence, mortality, and worldwide burden: an ecological analysis from the Global Burden of Disease Study 2017. BMC Med 2019; 17(1): 191, doi: 10.1186/s12916-019-1397-3.

8. Abbas M, Malicke DT, Schramski JT. Stroke Anticoagulation. 2020 Oct 20. In: StatPearls [Internet]. Treasure Island (FL): StatPearls Publishing, PMID: 31751016. Available from URL: https://pubmed.ncbi.nlm.nih.gov/31751016/.

9. Pastori D, Eikelboom JW, Anand SS, et al. Management of patients with asymptomatic and symptomatic carotid artery disease: update on anti-thrombotic therapy. Thromb Haemost 2019; 119(4): 576-585, doi: 10.1055/s-0039-1678527.

10. Spacek $M$, Zemanek $D$, Hutyra $M$, et al. Vulnerable atherosclerotic plaque - a review of current concepts and advanced imaging. Biomed Pap Med Fac Univ Palacky Olomouc Czech Repub 2018; 162(1): 10-17, doi: 10.5507/bp.2018.004.

11. Guzik A, Bushnell C. Stroke epidemiology and risk factor management. Continuum (Minneap Minn) 2017; 23(1): 15-39, doi: 10.1212/ CON.0000000000000416.

12. Janczak D, Malinowski M, Ziomek A, et al. Carotid artery stenting versus endarterectomy for the treatment of both symptomatic and asymptomatic patients with carotid artery stenosis: 2 years' experience in a high-volume center. Adv Clin Exp Med 2018; 27(12): 1691-1695, doi: 10.17219/acem/75902.

13. Lamanna A, Maingard J, Barras CD, et al. Carotid artery stenting: current state of evidence and future directions. Acta Neurol Scand 2019; 139(4): 318-333, doi: 10.1111/ane.13062.

14. Wong KS, Caplan LR, Kim JS. Stroke mechanisms. Front Neurol Neurosci 2016; 40: 58-71, doi: 10.1159/000448302.

15. Albright KC, Huang L, Blackburn J, et al. Racial differences in recurrent ischemic stroke risk and recurrent stroke case fatality. Neurology 2018; 91(19): e1741-e1750, doi: 10.1212/wnl.0000000000006467.

16. Katano $\mathrm{H}$, Mase $\mathrm{M}$, Nishikawa $\mathrm{Y}$, et al. Analysis of recurrent stenosis after carotid endarterectomy featuring primary plaque calcification. Neurosurgery 2017; 80(6): 863-870, doi: 10.1093/neuros/nyw119.

17. Cheng SF, Brown MM. Contemporary medical therapies of atherosclerotic carotid artery disease. Semin Vasc Surg 2017; 30(1): 8-16, doi: 10.1053/j.semvascsurg.2017.04.005.

18. Murray CSG, Nahar T, Kalashyan H, et al. Ultrasound assessment of carotid arteries: current concepts, methodologies, diagnostic criteria, and technological advancements. Echocardiography 2018; 35(12): 2079-2091, doi: 10.1111/echo.14197.

19. Population census in Kazakhstan. 2009 [cited 09.09.2020]. Available from URL: https://stat.gov.kz/.

20. Nikolaev AY, Solodilov RO. [Reliability of the international physical activity questionnaire (ipaq-ru) as applied to sample student respondents]. Surgut State Univer J 2016; (3): 116-119 (in Russian).

21. Lu MY, Chen $\mathrm{CH}$, Yeh SJ, et al. Comparison between in-hospital stroke and community-onset stroke treated with endovascular thrombectomy. PLOS ONE 2019; 14(4): e0214883, doi: 10.1371/journal.pone.0214883.

22. Republican Center for health development. Clinical protocol for diagnosis and treatment of the Ministry of Healthcare of the Republic of Kazakhstan "Aterosclerosis of other arteries" No. 18 dated November 30, 2015 [cited 23.09.2020]. Available from URL: http://www. rcrz.kz/index.php/en/.

23. Barnett HJ, Taylor DW, Eliasziw M, et al. Benefit of carotid endarterectomy in patients with symptomatic moderate or severe stenosis. North American Symptomatic Carotid Endarterectomy Trial Collaborators. N Engl J Med 1998; 339(20): 1415-1425, doi: 10.1056/ nejm199811123392002.

24. Randomised trial of endarterectomy for recently symptomatic carotid stenosis: final results of the MRC European Carotid Surgery Trial (ECST). Lancet 1998; 351(9113): 1379-1387.

25. Hathout GM, Fink JR, El-Saden SM, et al. Sonographic NASCET index: a new doppler parameter for assessment of internal carotid artery stenosis. AJNR Am J Neuroradiol 2005; 26(1): 68-75.

26. Puz $\mathrm{P}$, Urbanek $\mathrm{T}$, Ziaja $\mathrm{D}$, et al. Factors associated with the symptomatic status of carotid artery stenosis: identification in a crosssectional study and development of a scoring system. Pol Arch Intern Med 2020, doi: 10.20452/pamw.15676.

27. Pawlik A, Januszek R, Ruzsa Z, et al. Gender differences and long-term clinical outcomes in patients with chronic total occlusions of infrainguinal lower limb arteries treated from retrograde access with peripheral vascular interventions. Adv Med Sci 2020; 65(1): 197-201, doi: 10.1016/j.advms.2020.01.004.

28. Tromba L, Tartaglia F, Blasi S, et al. Is carotid stenosis in women a gender-related condition? J Womens Health 2016; 25(4): 348-354, doi: 10.1089/jwh.2015.5300.

29. Luo J, Cui W, Ding Y, et al. The association between smoking status and carotid artery plaque in rural areas of Eastern part of China. Zhonghua Yu Fang Yi Xue Za Zhi 2015; 49(3): 243-247.

30. Chen $\mathrm{CY}$, Weng WC, Wu CL, et al. Association between gender and stoke recurrence in ischemic stroke patients with high-grade carotid artery stenosis. J Clin Neurosci 2019; 67: 62-67, doi: 10.1016/j.jocn.2019.06.021.

31. Zirak MR, Mehri S, Karimani A, et al. Mechanisms behind the atherothrombotic effects of acrolein, a review. Food Chem Toxicol 2019; 129: 38-53, doi: 10.1016/j.fct.2019.04.034.

32. Hackshaw A, Morris JK, Boniface S, et al. Low cigarette consumption and risk of coronary heart disease and stroke: meta-analysis of 141 cohort studies in 55 study reports. BMJ 2018; 360: j5855, doi: 10.1136/bmj.j5855.

33. Britton A, Hardy R, Kuh D, et al. Twenty-year trajectories of alcohol consumption during midlife and atherosclerotic thickening in early old age: findings from two British population cohort studies. BMC Med 2016; 14(1): 111, doi: 10.1186/s12916-016-0656-9.

34. Schultheis M, Saadat S, Dombrovskiy V, et al. Carotid stenosis in cardiac surgery - no difference in postoperative outcomes. Thorac Cardiovasc Surg 2018; 66(3): 255-260, doi: 10.1055/s-0036-1571851.

35. Xia X, Yue W, Chao B, et al. Prevalence and risk factors of stroke in the elderly in Northern China: data from the National Stroke Screening Survey. J Neurol 2019; 266(6): 1449-1458, doi: 10.1007/s00415-019-09281-5. 
36. Akhtar N, Kamran S, Singh R, et al. The impact of diabetes on outcomes after acute ischemic stroke: a prospective observational study. J Stroke Cerebrovasc Dis 2019; 28(3): 619-626, doi: 10.1016/j.jstrokecerebrovasdis.2018.11.003.

37. Boehme AK, Esenwa C, Elkind MS. Stroke risk factors, genetics, and prevention. Circ Res 2017; 120(3): 472-495, doi: 10.1161/circresaha.116.308398.

38. Jeong M-J, Kwon SU, Kim M-J, et al. Effects of patient age on outcomes after carotid endarterectomy: a retrospective, single-center study in Korea. Medicine 2019; 98(32): e16781, doi: 10.1097/md.0000000000016781.

39. Texakalidis $\mathrm{P}$, Giannopoulos $\mathrm{S}$, Jonnalagadda AK, et al. Carotid artery endarterectomy versus carotid artery stenting for restenosis after carotid artery endarterectomy: a systematic review and meta-analysis. World Neurosurg 2018; 115: 421-429, doi: 10.1016/j. wneu.2018.02.196.

40. Barboza MA, Chang J, Hernández A, et al. Safety of dual antiplatelet therapy after carotid endarterectomy for prevention of restenosis: a single center experience. J Vasc Interv Neurol 2016; 9(2): 5-9.

41. Constantinou J, Jayia P, Hamilton G. Best evidence for medical therapy for carotid artery stenosis. J Vasc Surg 2013; 58(4): 1129-1139, doi: 10.1016/j.jvs2013.06.085.

42. Lazaros G, Oikonomou E, Vogiatzi G, et al. The impact of sedentary behavior patterns on carotid atherosclerotic burden: implications from the Corinthia epidemiological study. Atherosclerosis 2019; 282: 154-161, doi: 10.1016/j.atherosclerosis.2019.01.026.

43. Cleland C, Ferguson S, Ellis G, et al. Validity of the International Physical Activity Questionnaire (IPAQ) for assessing moderate-tovigorous physical activity and sedentary behaviour of older adults in the United Kingdom. BMC Med Res Methodol 2018; 18(1): 176, doi: 10.1186/s12874-018-0642-3.

44. Nazari SSH, Mokhayeri Y, Mansournia MA, et al. Associations between dietary risk factors and ischemic stroke: a comparison of regression methods using data from the Multi-Ethnic Study of Atherosclerosis. Epidemiol Health 2018; 40: e2018021, doi: 10.4178/epih. e2018021.

45. Tong TYN, Appleby PN, Bradbury KE, et al. Risks of ischaemic heart disease and stroke in meat eaters, fish eaters, and vegetarians over 18 years of follow-up: results from the prospective EPIC-Oxford study. BMJ 2019; 366: 14897, doi: 10.1136/bmj.14897.

46. Herrington W, Lacey B, Sherliker P, et al. Epidemiology of atherosclerosis and the potential to reduce the global burden of atherothrombotic disease. Circ Res 2016; 118(4): 535-546, doi: 10.1161/circresaha.115.307611.

47. Finn C, Giambrone AE, Gialdini G, et al. The association between carotid artery atherosclerosis and silent brain infarction: a systematic review and meta-analysis. J Stroke Cerebrovasc Dis 2017; 26(7): 1594-1601, doi: 10.1016/j.jstrokecerebrovasdis.2017.02.028.

48. Lee PH, Macfarlane DJ, Lam TH, et al. Validity of the International Physical Activity Questionnaire Short Form (IPAQ-SF): a systematic review. Int J Behav Nutr Phys Act 2011; 8: 115, doi: 10.1186/1479-5868-8-115.

49. Frank U, Nikol S, Belch J, et al. ESVM Guideline on peripheral arterial disease. VASA Zeitschrift fur Gefasskrankheiten 2019; 48(Suppl. 102): 1-79, doi: 10.1024/0301-1526/a000834.

50. Myslinski W, Stanek A, Feldo M, et al. Ankle-Brachial Index as the best predictor of first acute coronary syndrome in patients with treated systemic hypertension. Biomed Res Int 2020; 2020: 6471098, doi: 10.1155/2020/6471098.

Tables: 3

Figures: 1

References: 50

Received: 11.12 .2020

Reviewed: 31.12 .2020

Accepted: 15.03.2021

Address for correspondence:

Shynar Tanabayeva, MD

Department of Medicine

S. D. Asfendiyarov Kazakh National Medical University

94, Tole-bi str.

Almaty 050020

Republic of Kazakhstan

Tel.: +7 7772569060

E-mail: shynar.tanabaeva@mail.ru 